\title{
Expression of CD44 in sheep oocytes and preimplantation embryos
}

\author{
J.V. Luz, A.S. Alcântara-Neto, R.I.T.P. Batista, J.M.G. Souza, \\ D.I.A. Teixeira, L.M. Melo and V.J.F. Freitas
}

Laboratório de Fisiologia e Controle da Reprodução, Faculdade de Veterinária, Universidade Estadual do Ceará, Fortaleza, CE, Brasil

Corresponding author: V.J.F. Freitas

E-mail: vicente.freitas@uece.br

Genet. Mol. Res. 11 (2): 799-809 (2012)

Received January 10, 2011

Accepted June 27, 2011

Published April 3, 2012

DOI http://dx.doi.org/10.4238/2012.April.3.2

\begin{abstract}
The CD44 family belongs to a larger group of hyaluronic acid-binding proteins and plays important roles in oocyte maturation, fertilization and preimplantational embryo development. We analyzed the CD44 receptor in sheep oocytes and embryos. Immature oocytes $(\mathrm{N}=66)$ were obtained from a local abattoir; mature oocytes $(\mathrm{N}=35)$ and embryos $(\mathrm{N}=41)$ were obtained by laparotomy from adult hair ewes submitted to ovarian stimulation treatment. The CD44 mRNA was detected by hemi-nested PCR, after reverse transcription, while proteins were located by indirect immunofluorescence, using anti-human CD44 monoclonal antibody. Human lymphocytes and immature bovine oocytes were used as positive and negative controls, respectively. Assessment of the oocyte nuclear stages as well as classification of the embryonic development stage were made with Hoechst 33342 staining. Indirect immunofluorescence detected CD44 expression on the surface of mature oocytes and embryos; immature oocytes did not take up the stain. These findings were supported by the RT-PCR data, which showed no mRNA templates for CD44, even after two consecutive amplifications, in material from immature oocytes and cumulus cells.
\end{abstract}


The CD44 amplicons were detected after a second hemi-nested PCR in mature oocytes and embryos. The finding of CD44 in mature oocytes and preimplantational embryos could reflect the expression profile of hyaluronic acid during terminal folliculogenesis and preimplantational embryo development in sheep.

Key words: Gene expression; Hemi-nested PCR; Sheep; Indirect immunofluorescence

\section{INTRODUCTION}

Oocyte maturation is crucial for nuclear maturation, successful fertilization and early embryo development (Gandolfi and Gandolfi, 2001). The competence of an oocyte is mainly characterized by cytoplasmic maturation, which involves oocyte growth, accumulation of specific mRNA and proteins needed for the development of oocyte and consequently the newly produced embryo (Hyttel et al., 1997).

The communication between the oocyte and the granulosa cells surrounding is crucial for the acquisition of oocyte competence (Assidi et al., 2008). The communication between the oocyte and the granulosa cells surrounding is crucial for the acquisition of oocyte competence (Assidi et al., 2008). One way of oocyte and cumulus cells communication is characterized by the secretion of several growth factors such as glycosaminoglycans (GAGs), which play an important role in proliferation and differentiation of a variety of cell types (Jackson et al., 1991).

Among the GAGs, hyalurunic acid (HA) is a high molecular weight polysaccharide found in the extracellular matrix of most animal tissues and is one of the most abundant GAGs in the uterine, oviductal and follicular fluids in woman (Ohta et al., 2001), mouse (Sato et al., 1987), sow (Archibong et al., 1989), and cow (Lee and Ax, 1984). During the process of ovulation, cumulus cells secrete HA (Salustri et al., 1990) that actively participates in processes of cytoskeletal modification, gap junction losses that accompany cumulus expansion in cumulus-oocyte complexes (COCs) and oocyte meiotic progression (Allworth and Albertini, 1993). The expansion of cumulus cells may be positively correlated to the ovulation, fertilization, and subsequent zygote development (Chen et al., 1993). The degree of cumulus cells expansion if often cited as a major indicator oocyte selection for in vitro fertilization protocols (Yokoo et al., 2010). It has also been demonstrated that HA delays death and prevents fragmentation of porcine oocytes (Sato et al., 1994; Tunjung et al., 2009) and plays a role in cell migration during the early embryonic development (Peterson et al., 1993). Moreover, HA added to the culture medium supports the development of 1- and 2-cell porcine embryos (Miyano et al., 1994) as well as improves in vitro bovine embryo development to the blastocyst stage (Furnus et al., 1998).

HA mainly binds to CD44, which is a glycoprotein widely expressed on the surface of many mammalian cells. CD44 exists as multiple isoforms expressed in a specific manner for different cell types. These isoforms result from splicing and post-translational modifications, where they can be differently glycosylated (Kaya et al., 2001). Cell surface glycoprotein CD44 is present in mature oocytes and preimplantation embryos in some species of mammals such as in humans (Campbell et al., 1995), bovine (Furnus et al., 2003), porcine (Toyokawa et al., 
2005), and mouse (Wheatley et al., 1993). Furthermore, CD44 was not detected in immature oocytes in porcine (Yokoo et al., 2007), bovine (Furnus et al., 2003), mice (Fulop et al., 1997), and humans (Campbell et al., 1995). These data indicate that CD44 is expressed during the maturation process suggesting its importance in this phase. It is reasonable to assume that HA profile is directly proportional to the amount of CD44 in somatic cells surrounding the growing oocyte.

No previous attempt has been made in sheep to analyze CD44 receptor expression in these structures. Our hypothesis is that, in sheep, both oocytes and preimplantation embryos express the hyaluronan receptor after in vivo maturation. Therefore, this study was carried out to investigate whether CD44 mRNA is produced in immature and mature oocytes and preimplantation embryos in sheep, by hemi-nested PCR, coupled to reverse transcription, and if the protein receptor is present in the membranes, using immunofluorescent techniques.

\section{MATERIAL AND METHODS}

\section{Chemicals and reagents}

All chemicals and reagents were purchased from Sigma Chemical Co. (St. Louis, MO, USA) unless otherwise indicated.

\section{Locality and bioethics}

The study was performed in the facilities of the Laboratory of Physiology and Control of Reproduction (LFCR), located in Fortaleza, Brazil, at $3^{\circ} 47^{\prime} 38^{\prime \prime} \mathrm{S}$ and $38^{\circ} 33^{\prime 2} 9^{\prime \prime} \mathrm{W}$. Studies were approved by the Institutional Animal Care and Use Committee at the State University of Ceará (CEUA-UECE) and performed according to the guidelines from the animal care (Van Zutphen and Balls, 1997).

\section{Experimental design}

Immature oocytes were obtained from abattoir ovaries whereas mature oocytes from hormonally stimulate hair ewes. Preimplantation embryos were recovered from donors submitted to a superovulation treatment. All these structures were submitted to hemi-nested PCR analysis in order to detect the presence of CD44 receptor and also to indirect immunofluorescence to identify its localization. Human lymphocytes were isolated from heparinized peripheral blood by separation in a Ficoll-Paque PLUS (GE Health Care-BioSciences, Uppsala, Sweden) density gradient according to manufacturer instructions. After dilution in Dulbecco's modified phosphate-buffered saline (DMPBS; Nutricell, São Paulo, Brazil), lymphocytes were used as positive control (Wagner et al., 1998). Conversely, immature bovine oocytes were used as negative control (Furnus et al., 2003). Indirect immunofluorescence analysis detected the sheep CD44 receptor using an anti-human CD44 antibody (clone DF1485), due to its cross-reaction with an antibody raised against the human receptor (Kimura et al., 2007).

\section{Immature oocytes}

Thirty adult hair ewes' ovaries were obtained from a local abattoir and transported 
to the laboratory in sterile saline $(0.9 \% \mathrm{NaCl})$ solution containing antibiotics at $37^{\circ} \mathrm{C}$, within $3 \mathrm{~h}$ of slaughter. Ovarian follicles ( 2 to $5 \mathrm{~mm}$ in diameter) were punctured and COCs were aspirated using a 19-gauge needle coupled to a sterile tube containing $4 \mathrm{~mL}$ DMPBS under gentle vacuum $(30 \mathrm{mmHg}$ ). Follicular contents were poured onto a Petri dish and observed under a stereomicroscope (Nikon SMZ-800, Kawasaki, Japan) at 10 to 50X magnification. The COCs were located, washed eight times in DMPBS drops and evaluated regarding its quality. The COCs of grades I and II, according to Gibbons et al. (2007), were stripped mechanically by successive pipetting and the oocytes were immediately used for indirect immunofluorescence assays. Denude oocytes and its cumulus cells were separately frozen $\left(-80^{\circ} \mathrm{C}\right)$ until its use for nested PCR.

\section{In vivo matured oocytes}

Three hair ewes aging 1 to 5 years were used as mature oocyte donors. Estrus was synchronized with intravaginal sponge containing $60 \mathrm{mg}$ medroxyprogesterone acetate (Progespon, Sintex, Buenos Aires, Argentina) inserted for 14 days. In addition, follicular development was stimulated by a gonadotrophin treatment consisting in a multi-injection regime of a total $150 \mathrm{mg}$ pFSH (Folltropin-V, Vetrepharm, Ontario, Canada) administered intramuscularly initially $48 \mathrm{~h}$ before removing the sponge, in decreasing doses twice daily for three days $(30 / 30,25 / 25$ and $20 / 20 \mathrm{mg}$ ). Estrus was detected at $24 \mathrm{~h}$ after sponge removal using a teaser. The oocytes were collected at $96 \mathrm{~h}$ after sponge removal by laparotomy followed by oviductal flushing. The oviduct was flushed retrogradely with $15-20 \mathrm{~mL}$ DMPBS and the recovered structures were evaluated under a stereomicroscope at 10 to $50 \mathrm{X}$ magnification. Matured oocytes were identified by the presence of the first polar body and expanded cumulus cells. The structures were stripped mechanically by successive pipetting and the denuded oocytes were immediately used for indirect immunofluorescence or frozen $\left(-80^{\circ} \mathrm{C}\right)$ until its use for nested PCR.

\section{In vivo embryo production}

Four hair ewes aging 1 to 5 years were submitted to the same hormonal treatment as previously described. Additionally, females were mated at the beginning of estrus and $24 \mathrm{~h}$ afterward, using rams of proven fertility. Embryo recovery was performed by laparotomy six days after the first mating. Shortly, after genital tract exposure, each uterine horn was flushed retrogradely with 20-40 mL DMPBS. Embryo quality and development stage were evaluated under a stereomicroscope at 10 to $50 \mathrm{X}$ magnification. Only embryos at the morula stage were subsequently used for indirect immunofluorescence or frozen $\left(-80^{\circ} \mathrm{C}\right)$ for nested PCR.

\section{RNA extraction}

Total RNA was prepared from pooled immature oocytes $(\mathrm{N}=46)$, mature oocytes ( $\mathrm{N}$ $=10)$, cumulus cells obtained from immature COCs $(\mathrm{N}=46)$, and embryos $(\mathrm{N}=11)$ using the RNeasy micro kit (Qiagen, Valencia, CA, USA) according to manufacturer instructions. Briefly, $75 \mu \mathrm{L}$ lysis buffer was added to each frozen sample and the lysate was diluted 1:1 with $70 \%$ ethanol and transferred to a spin column. Genomic DNA was degraded using RNase-free 
DNase for $15 \mathrm{~min}$ at room temperature. After three washes, the RNA was eluted with $10 \mu \mathrm{L}$ RNase-free water.

\section{Reverse transcription}

Prior to reverse transcription, RNA samples from each cell type, $500 \mathrm{ng}$ oligo-dT primer (Promega, Madison, WI, USA) and sterile MilliQ water (to a total volume of $5 \mu \mathrm{L}$ ) were heated to $70^{\circ} \mathrm{C}$ for $10 \mathrm{~min}$ to disrupt possible secondary structures and then snap-cooled on ice. Thereafter, $1 \mu \mathrm{L}$ Improm II (Promega) in reverse transcription buffer was combined with $0.5 \mathrm{mM}$ of each dNTP, $3 \mathrm{mM} \mathrm{MgCl} 2$ (Promega), $2 \mathrm{U} / \mu \mathrm{L}$ RNaseOUT (Invitrogen, Carlsbad, CA, USA), and RNase-free water to make a final reaction volume of $20 \mu \mathrm{L}$. Reverse transcription was performed at $42^{\circ} \mathrm{C}$ for $60 \mathrm{~min}$, followed by $70^{\circ} \mathrm{C}$ for $15 \mathrm{~min}$. The first-strand cDNA products were then stored at $-80^{\circ} \mathrm{C}$ for later use as template for hemi-nested PCR. Negative controls or reverse-transcribed blanks were prepared under the same conditions, but without inclusion of reverse transcriptase.

\section{Hemi-nested PCR}

The cDNA amplification was conducted with two rounds of hemi-nested using PCR primers to increase the specificity and yield of the PCR product. The total $20-\mu \mathrm{L}$ PCR product contained $2 \mu \mathrm{L}$ reverse-transcribed cDNA, 0.5 IU GoTaq DNA Polymerase (Promega), $0.2 \mathrm{mM}$ of each dNTP, $2 \mathrm{mM} \mathrm{MgCl}{ }_{2}$ and $0.2 \mu \mathrm{M}$ of each primer (Table 1). For both PCR, the amplification parameters consisted of an initial denaturation at $94^{\circ} \mathrm{C}$ for $4 \mathrm{~min} ; 30$ cycles of denaturation at $94^{\circ} \mathrm{C}$ for $50 \mathrm{~s}$, annealing at $60^{\circ} \mathrm{C}$ for $50 \mathrm{~s}$, and extension at $72^{\circ} \mathrm{C}$ for $50 \mathrm{~s}$, and a final extension at $72^{\circ} \mathrm{C}$ for $6 \mathrm{~min}$. For the hemi-nested PCR, $2 \mu \mathrm{L}$ primary product was added to $18 \mu \mathrm{L}$ freshly prepared mix, as above. The amplified product was subjected to $2 \%$ agarose gel electrophoresis using 100-bp DNA ladder (Invitrogen) as a reference for fragment size and stained with ethidium bromide. In order to produce visible amplicons, the second round of PCR was not necessary for $\beta$-actin gene.

Table 1. Primer sequence, annealing temperature and fragment size of both hemi-nested PCRs used to detect the presence of CD44 receptor in sheep immature and mature oocytes and embryos.

\begin{tabular}{|c|c|c|c|c|}
\hline Gene & Nested PCR step & Nucleotide sequence & GenBank accession No. & Product size (bp) \\
\hline \multirow[t]{4}{*}{ CD44 } & 1st PCR & 5'-CAACACCTCCCASTATGACAC-3' a & NM_001001391 & $570^{\mathrm{b}}$ \\
\hline & & 5'-TTCTTCTGCCCACACCTTCT-3' & $\overline{\text { EE765662 }}$ & \\
\hline & 2nd PCR & 5'-TGGCTGATCATCATCTTGGCA-3' & EE765662 & 92 \\
\hline & & 5'-TTCTTCTGCCCACACCTTCT-3' & EE765662 & \\
\hline \multirow[t]{2}{*}{ b-actin } & 1st PCR & 5'-CAACTGGGACGACATGGA-3' & NM_001009784 & 377 \\
\hline & & 5'-TGGTGGTGAAGCTGTAGC-3' & NM_001009784 & \\
\hline
\end{tabular}

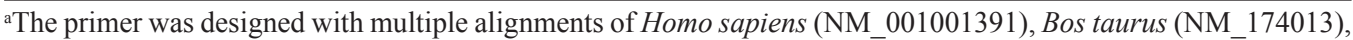
Mus musculus (NM_001177787), and Rattus norvergicus (NM_012924) CD44 genes. 'Product size expected for standard CD44 in Homo sapiens.

\section{Indirect immunofluorescence}

Sheep immature $(\mathrm{N}=20)$, mature oocytes $(\mathrm{N}=15)$ and embryos $(\mathrm{N}=20)$ were washed 
eight times in DMPBS drops and deposited on slide coated with poly-L-lysine (Polysciences Inc., Eppelheim, Germany). The structures were fixed on $4 \%$ paraformaldehyde, $\mathrm{pH} 7.4$, in DMPBS, at $25^{\circ} \mathrm{C}$ for 20 min, permeabilized with $1 \%(\mathrm{v} / \mathrm{v})$ Triton X-100 and then washed three times in DMPBS. The specimens were then incubated for $3 \mathrm{~h}$ at $25^{\circ} \mathrm{C}$ with anti-human CD44 monoclonal antibody, DF1485 (Visionbiosystems Novocastra, Newcastle upon Tyne, UK), diluted to 1:40 in DMPBS containing 3\% bovine serum albumin (BSA). After three washings in DMPBS, oocytes and embryos were incubated in the dark for $1 \mathrm{~h}$ with anti-mouse immunoglobulin $\mathrm{G}(\mathrm{IgG})$ antibody conjugated with fluorescein isothiocyanate (FITC) diluted 1:100 in DMPBS containing 3\% BSA. After three washings with DMPBS, the specimens were stained with Hoechst 33342 at $1 \mu \mathrm{g} / \mathrm{mL}$ for $15 \mathrm{~min}$, for determination of their development stage. Finally, the slides were mounted with $90 \%$ glycerol in DMPBS and examined under a microscope (Nikon Eclipse E400, Tokyo, Japan) with epifluorescence illumination, using a B-2A filter for fluorescein (excitation wave length: 450 to $490 \mathrm{~nm}$ ) and UV-2A filter for Hoechst 33342 (excitation wave length: 330 to $380 \mathrm{~nm}$ ). The images were recorded using the Nikon DS-5M-L1 system coupled to the microscope. Additionally, to exclude the possibility of false-positive fluorescence due to non-specific binding with the secondary antibody or because of paraformaldehyde-induced autofluorescence, slides were prepared with both sheep oocytes and embryos, as well as with human lymphocytes and bovine oocytes (10 structures for each group), which were treated in the same manner as described above, but omitting the primary antibody or primary and secondary antibodies, respectively.

\section{RESULTS}

Grade I and II COCs $(\mathrm{N}=76)$ were recovered from abattoir-derived ovaries, providing a mean recovery of $2.5 \mathrm{COCs} /$ ovary. A total of 45 ovulations were achieved and 35 oocytes were recovered regarding the in vivo production of mature oocytes and corresponding to a recovery rate of $77.8 \%$. Embryo donors had a total of 60 corpora lutea and 41 embryos were recovered, resulting in a recovery rate of $68.3 \%$.

Expression analysis by hemi-nested PCR detected the presence of CD44 mRNA in mature oocytes and preimplantation embryos, whereas it was absent in immature oocytes (Figure 1). Additionally, the CD44 transcripts were also detected in human lymphocytes (positive control) in both amplifications of hemi-nested PCR.

Fluorescent staining with Hoechst 33342 allowed the visualization of the germinal vesicle in immature oocytes (Figure 2, B.2 and C.2), metaphase plate and/or polar body in mature oocytes (Figure 2, D.2) as well as the approximate number of nuclei at the preimplantation embryos (Figure 2, E.2). In addition, this nuclear staining confirmed the majority of lymphocytes isolated from human peripheral blood (Figure 2, A.2). Moreover, images of embryos stained with Hoechst 33342 (Figure 2, E.2) were acquired in bright field (Figure 2, E.1). The images showed to be at the morula stage. A homogeneous staining was observed in mature oocytes (Figure 2, D.3) and embryos (Figure 2, E.3), where the fluorescent signal was the most intense in the first group. After removal of the baseline signal from autofluorescence, there was no FITC staining of immature oocytes of ewes (Figure 2, C.3) and cows (Figure 2, B.3). However, human lymphocytes showed an intense fluorescent staining, distributed mainly in the peripheral region (Figure 2, A.3). No structure showed fluorescence signal as result of non-specific binding of secondary antibody. 


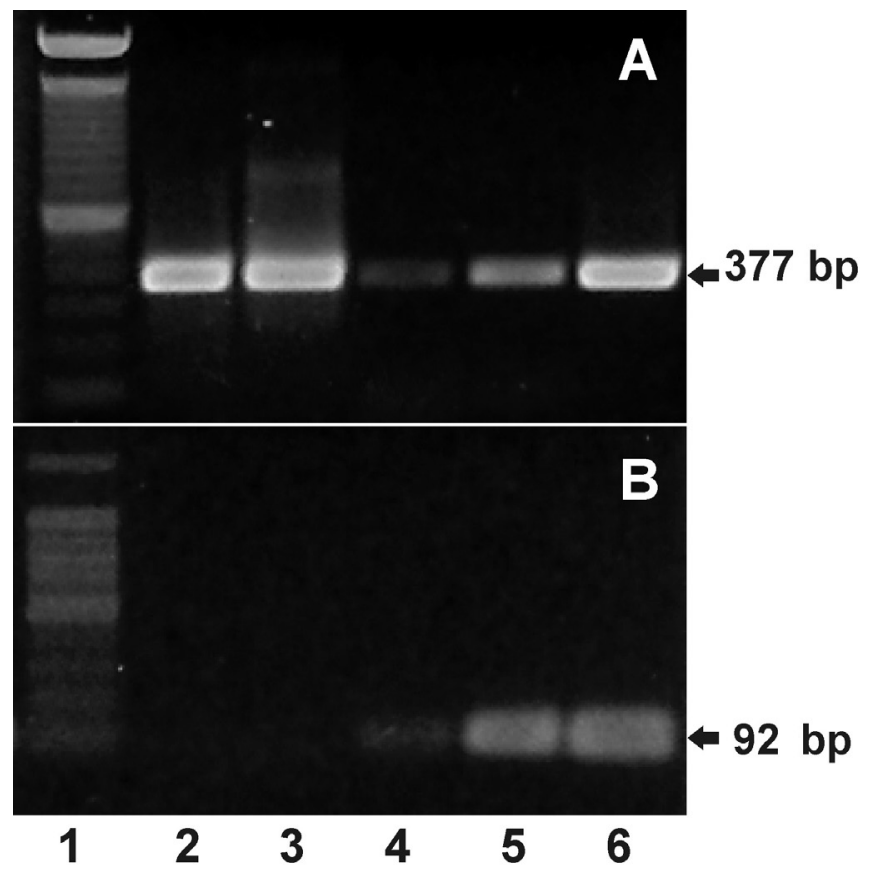

Figure 1. Detection of CD44 receptor by hemi-nested PCR amplifications in sheep oocytes and embryos. Electrophoretic analysis of the $\beta$-actin (A) and CD44 (B) amplicons produced using cumulus cells of immature cumulus-oocyte complexes (lane 2), immature oocytes (lane 3), mature oocytes (lane 4), preimplantation embryos (lane 5), and human lymphocytes (lane 6) cDNA as template. Lane $1=100$-bp DNA ladder.

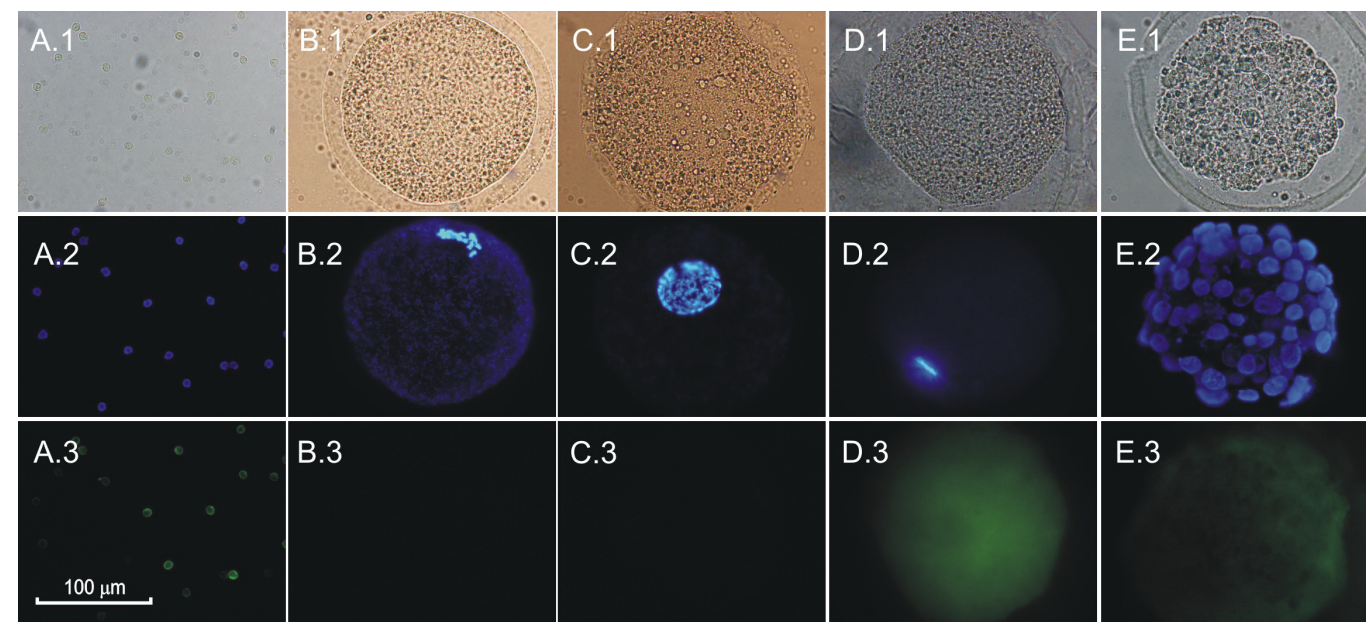

Figure 2. Detection of CD44 receptor by indirect immunofluorescence staining (FITC) in sheep oocytes and embryos. Columns show human lymphocytes (positive control, A.1 to A.3), immature bovine oocyte (negative control, B.1 to B.3), immature (C.1 to C.3) and mature sheep oocytes (D.1 to D.3) and sheep compact morula (E.1 to E.3). Photographs of representative structures in bright field (A.1 to E.1), epifluorescence for Hoechst 33342 (A.2 to E.2) and FITC (A.3 to E.3). 


\section{DISCUSSION}

In the present study, for the first time to our knowledge, we demonstrated that CD44 is expressed on sheep mature oocytes and embryos. Using hemi-nested PCR and indirect immunofluorescence, it was detected the expression at transcript and mature protein levels, respectively. The same findings were already reported in matured oocytes in other mammalian species such as human (Campbell et al., 1995), rat (Borg and Holland, 2008), bovine (Schoenfelder and Einspanier, 2003), and porcine (Kimura et al., 2002; Yokoo et al., 2007) and in different preimplantation stages of embryos in bovine (Furnus et al., 2003), porcine (Toyokawa et al., 2005) and human (Campbell et al., 1995).

On the other hand, we found that neither CD44 mRNA nor transmembrane protein were detected in immature oocytes. This is coherent since immature oocytes should be in contact with surrounding granulose cells to allow nutrient passage and reach its proper development. This agrees with data previously reported for other mammalian species such as porcine (Yokoo et al., 2007), bovine (Furnus et al., 2003), mice (Fulop et al., 1997), and human (Campbell et al., 1995), who did not detect CD44 in immature oocytes.

No studies have established the role of the HA-CD44 system in oocyte maturation. However, Slevin et al. (1998) demonstrated that the degradation product of HA (3 to 10 disaccharides) induces the phosphorylation of the CD44 receptor, leading to the activation of kinase proteins, which are subsequently translocated to nucleus. This cascade is important for mitogenic signal transduction and sufficient for the induction of cell proliferation through the stimulation of proto-oncogenic transcription factors (Daum et al., 1994); furthermore, it plays a crucial role in activation and stabilization of the M phase promoting factor (MPF) during oocyte maturation (Inoue et al., 1998). Since the predominant component in the expanded cumulus is HA (Salustri et al., 1989), this probably explains the presence of the CD44 receptor in mature oocytes.

It is already known that CD44 has an influence on the expansion of the cumulus cells during the oocyte maturation (Yokoo et al., 2002), on fertility and quality of oocytes (Goodison et al., 1999). Since the hyaluronan-CD44 interaction is involved in the induction of meiotic resumption it was presumed that this receptor was expressed in the oocytes. However, it was demonstrated that this receptor is present only in cumulus cells, not in the oocyte. Recent studies have shown that the meiotic maturation of oocytes is also subject to regulation by the somatic compartment of the ovarian follicle. MPF activation at the onset of meiotic resumption is inhibited by intra-oocyte cAMP, which is transferred from cumulus cells via gap junctional communication within COCs. Interruption of gap junctions in the COCs, which occurs in response to the pre-ovulatory surge of gonadotropins (Schoenfelder and Einspanier, 2003; Assidi et al., 2008; Tunjung et al., 2009), leads to a drop in the intra-oocyte concentration of cAMP, followed by MPF activation and meiotic resumptions. The reduction of the intra-oocyte cAMP concentration was suppressed by the inhibition of the interaction between hyaluronan and CD44. This result supports the concept that hyaluronan-CD44 interaction is involved in the regulation of gap junctional communication and the termination of the cAMP flux from cumulus cells to oocytes (reviewed by Yokoo et al., 2010).

$\mathrm{Li}$ et al. (2008) reported that early production of HA occurs approximately $18 \mathrm{~h}$ after the onset of maturation, stimulated by the growth differentiation factor 9 (GDF9) and bone morphogenetic protein 15 (BMP15), which induce hyaluron synthase enzyme expression, responsible for synthesis of HA. Optimal expansion of cultured COCs requires the presence of 
substrates of HA synthesis and an expanded cumulus mass may positively influence oocyte viability (Chen et al., 1993). HA produced naturally by granulosa cells also prevents fragmentation or segmentation of oocytes in vitro (Sato et al., 1987).

CD44 also plays a role on embryo development up to blastocyst stage (Yokoo et al., 2002; Kimura et al., 2007). Furnus et al. (1998) supplemented $1 \mathrm{mg} / \mathrm{mL}$ HA to the culture medium and found the rate of bovine embryos that developed to the blastocyst stage higher than in medium alone. These authors reported that the incorporation of HA in a chemically defined medium clearly demonstrated the effect of HA in the improvement of blastocyst formation. This is in agreement with Miyano et al. (1994), who verified that the proportion of degenerated porcine embryos was lower in the presence than in the absence of HA. It has been suggested that HA might benefit embryo development per se or by regulating the action of factors synthesized by the embryo, acting in an autocrine way (Furnus et al., 2003).

The presence of CD44 in mature oocytes and preimplantational embryos suggests the expression profile of the HA during maturation and preimplantational development. The findings of this study could be useful in the definition, investigation and also understanding of the physiological role of CD44 in the reproductive processes involved in the ovine species. Further studies are necessary to clarify the events in which CD44 and HA are involved during maturation and preimplantational embryo development in sheep.

\section{ACKNOWLEDGMENTS}

Research supported by the Conselho Nacional de Desenvolvimento Científico e Tecnológico (CNPq, Brasília, Brazil), Coordenação de Aperfeiçoamento de Pessoal de Nível Superior (PNPD/CAPES, Brasília, Brazil) and Fundação Cearense de Apoio ao Desenvolvimento Científico e Tecnológico (FUNCAP, Fortaleza, Brazil). The authors gratefully acknowledge the staff of the Laboratório de Fisiologia e Controle da Reprodução for management and other technical assistance with the animals needed for this project.

\section{REFERENCES}

Allworth AE and Albertini DF (1993). Meiotic maturation in cultured bovine oocytes is accompanied by remodeling of the cumulus cell cytoskeleton. Dev. Biol. 158: 101-112.

Archibong AE, Petters RM and Johnson BH (1989). Development of porcine embryos from one- and two-cell stages to blastocysts in culture medium supplemented with porcine oviductal fluid. Biol. Reprod. 41: 1076-1083.

Assidi M, Dufort I, Ali A, Hamel M, et al. (2008). Identification of potential markers of oocyte competence expressed in bovine cumulus cells matured with follicle-stimulating hormone and/or phorbol myristate acetate in vitro. Biol. Reprod. 79: 209-222.

Borg N and Holland M (2008). The effect of glycosaminoglycans on rat gametes in vitro and the associated signal pathway. Reproduction 135: 311-319.

Campbell S, Swann HR, Aplin JD, Seif MW, et al. (1995). CD44 is expressed throughout pre-implantation human embryo development. Hum. Reprod. 10: 425-430.

Chen L, Russell PT and Larsen WJ (1993). Functional significance of cumulus expansion in the mouse: roles for the preovulatory synthesis of hyaluronic acid within the cumulus mass. Mol. Reprod. Dev. 34: 87-93.

Daum G, Eisenmann-Tappe I, Fries HW, Troppmair J, et al. (1994). The ins and outs of Raf kinases. Trends Biochem. Sci. 19: 474-480.

Fulop C, Salustri A and Hascall VC (1997). Coding sequence of a hyaluronan synthase homologue expressed during expansion of the mouse cumulus-oocyte complex. Arch. Biochem. Biophys. 337: 261-266.

Furnus CC, de Matos DG and Martinez AG (1998). Effect of hyaluronic acid on development of in vitro produced bovine embryos. Theriogenology 49: 1489-1499. 
Furnus CC, Valcarcel A, Dulout FN and Errecalde AL (2003). The hyaluronic acid receptor (CD44) is expressed in bovine oocytes and early stage embryos. Theriogenology 60: 1633-1644.

Gandolfi TA and Gandolfi F (2001). The maternal legacy to the embryo: cytoplasmic components and their effects on early development. Theriogenology 55: 1255-1276.

Gibbons A, Pereyra BF, Cueto MI, Catala M, et al. (2007). Procedure for maximizing oocyte harvest for in vitro embryo production in small ruminants. Reprod. Domest. Anim. 42: 423-426.

Goodison S, Urquidi V and Tarin D (1999). CD44 cell adhesion molecules. Mol. Pathol. 52: 189-196.

Hyttel P, Fair T, Callesen H and Greve T (1997). Oocyte growth, capacitation and final maturation in cattle. Theriogenology 47: 23-32.

Inoue M, Naito K, Nakayama T and Sato E (1998). Mitogen-activated protein kinase translocates into the germinal vesicle and induces germinal vesicle breakdown in porcine oocytes. Biol. Reprod. 58: 130-136.

Jackson RL, Busch SJ and Cardin AD (1991). Glycosaminoglycans: molecular properties, protein interactions, and role in physiological processes. Physiol. Rev. 71: 481-539.

Kaya G, Laurini R, Chaubert P and Gross N (2001). Expression of CD44 and its isoforms in the fetal neuroblasts. Appl. Immunohistochem. Mol. Morphol. 9: 180-184.

Kimura N, Konno Y, Miyoshi K, Matsumoto H, et al. (2002). Expression of hyaluronan synthases and CD44 messenger RNAs in porcine cumulus-oocyte complexes during in vitro maturation. Biol Reprod. 66: 707-717.

Kimura N, Hoshino Y, Totsukawa K and Sato E (2007). Cellular and molecular events during oocyte maturation in mammals: molecules of cumulus-oocyte complex matrix and signalling pathways regulating meiotic progression. Soc. Reprod. Fertil. Suppl. 63: 327-342.

Lee CN and Ax RL (1984). Concentrations and composition of glycosaminoglycans in the female bovine reproductive tract. J. Dairy Sci. 67: 2006-2009.

Li HK, Kuo TY, Yang HS, Chen LR, et al. (2008). Differential gene expression of bone morphogenetic protein 15 and growth differentiation factor 9 during in vitro maturation of porcine oocytes and early embryos. Anim. Reprod. Sci. 103: 312-322.

Miyano T, Hiro-Oka RE, Kano K, Miyake M, et al. (1994). Effects of hyaluronic acid on the development of 1- and 2-cell porcine embryos to the blastocyst stage in vitro. Theriogenology 41: 1299-1305.

Ohta N, Saito H, Kaneko T, Yoshida M, et al. (2001). Soluble CD44 in human ovarian follicular fluid. J Assist. Reprod. Genet. 18: 21-25.

Peterson PE, Pow CS, Wilson DB and Hendrickx AG (1993). Distribution of extracellular matrix components during early embryonic development in the macaque. Acta Anat. 146: 3-13.

Salustri A, Yanagishita M and Hascall VC (1989). Synthesis and accumulation of hyaluronic acid and proteoglycans in the mouse cumulus cell-oocyte complex during follicle-stimulating hormone-induced mucification. J. Biol. Chem. 264: 13840-13847.

Salustri A, Ulisse S, Yanagishita M and Hascall VC (1990). Hyaluronic acid synthesis by mural granulosa cells and cumulus cells in vitro is selectively stimulated by a factor produced by oocytes and by transforming growth factor- $\beta$. J. Biol. Chem. 265: 19517-19523.

Sato E, Ishibashi T and Koide SS (1987). Prevention of spontaneous degeneration of mouse oocytes in culture by ovarian glycosaminoglycans. Biol. Reprod. 37: 371-376.

Sato E, Inoue M, Takahashi Y and Toyoda Y (1994). Glycosaminoglycans prevent induction of fragmentation of porcine oocytes stimulated by dibutyryl cyclic adenosine 3',5'-monophosphate in culture. Cell Struct. Funct. 19: 29-36.

Schoenfelder M and Einspanier R (2003). Expression of hyaluronan synthases and corresponding hyaluronan receptors is differentially regulated during oocyte maturation in cattle. Biol. Reprod. 69: 269-277.

Slevin M, Krupinski J, Kumar S and Gaffney J (1998). Angiogenic oligosaccharides of hyaluronan induce protein tyrosine kinase activity in endothelial cells and activate a cytoplasmic signal transduction pathway resulting in proliferation. Lab. Invest. 78: 987-1003.

Toyokawa K, Harayama H and Miyake M (2005). Exogenous hyaluronic acid enhances porcine parthenogenetic embryo development in vitro possibly mediated by CD44. Theriogenology 64: 378-392.

Tunjung WA, Yokoo M, Hoshino Y, Miyake Y, et al. (2009). Effect of hyaluronan to inhibit caspase activation in porcine granulosa cells. Biochem. Biophys. Res. Commun. 382: 160-164.

Van Zutphen LFM and Balls M (1997). Animal Alternatives, Welfare and Ethics. Elsevier, Amsterdam.

Wagner SN, Wagner C, Reinhold U, Funk R, et al. (1998). Predominant expression of CD44 splice variant v10 in malignant and reactive human skin lymphocytes. J. Invest. Dermatol. 111: 464-471.

Wheatley SC, Isacke CM and Crossley PH (1993). Restricted expression of the hyaluronan receptor, CD44, during postimplantation mouse embryogenesis suggests key roles in tissue formation and patterning. Development 119: 295-306. 
Yokoo M, Miyahayashi Y, Naganuma T, Kimura N, et al. (2002). Identification of hyaluronic acid-binding proteins and their expressions in porcine cumulus-oocyte complexes during in vitro maturation. Biol. Reprod. 67: 1165-1171.

Yokoo M, Shimizu T, Kimura N, Tunjung WA, et al. (2007). Role of the hyaluronan receptor CD44 during porcine oocyte maturation. J. Reprod. Dev. 53: 263-270.

Yokoo M, Kimura N and Sato E (2010). Induction of oocyte maturation by hyaluronan-CD44 interaction in pigs. $J$. Reprod. Dev. 56: 15-19. 